\title{
Effect of very high compaction pressures on the physical and mechanical properties of earthen materials
}

\author{
Agostino Walter Bruno ${ }^{1}$, Domenico Gallipoli ${ }^{1}$, Céline Perlot ${ }^{1}$ and Joao Mendes ${ }^{1}$ \\ ${ }^{1}$ Université de Pau et des Pays de I 'Adour, Laboratoire SIAME, 64600 Anglet, France
}

\begin{abstract}
The paper compares the effect of different compaction procedures on the porosity and mechanical characteristics of earthen materials. In a first series of tests, a very high static pressure, up to $100 \mathrm{MPa}$, is applied to the soil for a sufficient period of time to allow consolidation (hyper-compaction). This method produces materials with very high densities up to $2300 \mathrm{~kg} / \mathrm{m}^{3}$ and good mechanical properties, which are suitable for the construction of masonry structures. In a second series of tests, the soil is compacted according to the standard Proctor method, which is the reference compaction procedure for the design of geotechnical fills such as dams and embankments. In the Proctor method, the soil is dynamically compressed by means of a much lower effort compared to hyper-compaction. All specimens are equalized under identical hygro-thermal conditions and subjected to unconfined compression tests to measure stiffness and strength. It is shown that hyper-compacted specimens exhibit physical and mechanical properties that are comparable with those of traditional building materials for masonry structures. Finally, mercury intrusion porosimetry tests are performed to study the effect of the compaction method on the pore structure of the material.
\end{abstract}

\section{Introduction}

Earthen materials are widely used in civil engineering. Dams and embankments are among the most common earthen structures but dwellings made of raw earth are also spread worldwide. In all cases, the compaction process represents a crucial stage during material manufacturing. Compaction also affects the hydraulic behaviour by changing the porosity and fabric of the earthen material.

Current compaction methods produce mechanical properties that are weaker than those of conventional materials for masonry construction (e.g. fired bricks, stabilized earth or concrete blocks ). These methods must therefore be significantly enhanced if unstabilized earthen materials are to be widely used in the construction of large buildings.

A considerable number of studies have analysed the influence of compaction effort on the mechanical properties of earthen materials [1-5]. These studies agree that a higher compaction effort increases the dry density and, consequently, the stiffness and strength of the material. These studies also show that, for a given compaction effort, there is an optimum value of water content for which the highest density and the best mechanical properties are achieved.

Past studies have focused on the effect of compaction on the porosity and fabric of fine-grained soils, such as silty clays [6] or swelling clays [7], which are most relevant to geotechnical applications.
Relatively few studies however exist about the compaction of coarser soils used in the construction of raw earth dwellings.

In this context, the present work investigates the effect of different compaction methods on both the mechanical and microstructural properties of a relatively coarse soil suitable for raw earth construction. Two compaction methods are compared, namely the standard Proctor method, which represents a norm in geotechnical construction, and an innovative static compaction method applying very high levels of pressure (hypercompaction). As expected, the stiffness and strength of the material vary widely depending on the chosen compaction procedure, which confirms that material properties can be tailored to different applications by selecting an appropriate compaction procedure. For example, hyper-compaction generates mechanical properties that are comparable with those of conventional building materials. The effect of compaction procedure on pore fabric is also analysed by means of mercury intrusion porosimetry tests. Results from these tests confirm that, when compaction effort increases, the porosity reduces and the mechanical properties of the material improve.

Finally, it is observed that a higher compaction effort reduces the variability of physical and mechanical properties between specimens, thus facilitating the quality control of material properties.

\footnotetext{
a Corresponding author: agostinowalter.bruno@univ-pau.fr
} 


\section{Material and methods}

\subsection{Material}

The soil used in the present work has been provided by a brickwork factory from the region of Toulouse in France. Table 1 shows some of the relevant properties of the soil. The grain size distribution has been determined by both wet sieving and sedimentation in compliance with the norms XP P94-041 [8] and NF P 94-057 [9]. The plasticity properties of the fine fraction (i.e. fraction smaller than $400 \mu \mathrm{m}$ ) have been measured in agreement with the norm NF P94-051 [10]. In particular, the liquid limit, plastic limit and plasticity index have been determined as the average of four independent tests. The specific gravity of solid particles has been obtained by means of the pycnometer test according to the norm NF P 94-054 [11].

Bruno et al. [12] show that the grain size distribution and the plasticity properties of the material used in this work satisfy the requirements for raw earth construction [13-16].

Clay activity, defined as the ratio between the plasticity index and the clay fraction (i.e. the fraction smaller than $2 \mu \mathrm{m}$ ), is equal to 0.79 . This classifies the clay fraction as normally active [17], which is consistent with mineralogy information from the soil provider that indicates a predominantly illitic material with a small quantity of montmorillonite. Illite is a three-layers clay with good bonding characteristics and a limited swelling potential upon wetting, which makes it particularly suited to raw earth construction [18].

\subsection{Compaction procedure}

Hyper-compacted samples were statically compressed at pressure levels of $25 \mathrm{MPa}, 50 \mathrm{MPa}$ and $100 \mathrm{MPa}$. The lowest pressure level of $25 \mathrm{MPa}$ is comparable to that of the most powerful presses currently available on the market for the manufacture of compressed earth blocks. The other two pressure levels (chosen according to a geometrical progression with ratio of two) are, to the authors' knowledge, the highest ever applied during production of medium-scale compressed earth samples.

Prior to compaction, 500 grams of dry soil were mixed with the desired amount of water by using an electrical planetary mixer for at least 15 minutes. This

Table 1. Material properties.

\begin{tabular}{|c|c|c|}
\hline \multicolumn{3}{|c|}{ Grain size distribution } \\
\hline Gravel & $>2 \mathrm{~mm}$ & $0.4 \%$ \\
\hline Sand & $0.063-2 \mathrm{~mm}$ & $40.4 \%$ \\
\hline Silt & $0.002-0.063 \mathrm{~mm}$ & $42.9 \%$ \\
\hline Clay & $<0.002 \mathrm{~mm}$ & $16.3 \%$ \\
\hline \multicolumn{3}{|c|}{ Plasticity properties } \\
\hline \multicolumn{2}{|c|}{ Liquid limit, $\mathrm{w}_{\mathrm{L}}$} & $33.0 \%$ \\
\hline \multicolumn{2}{|c|}{ Plastic limit, $\mathrm{w}_{\mathrm{P}}$} & $20.1 \%$ \\
\hline \multicolumn{2}{|c|}{ Plasticity index, $\mathrm{I}_{\mathrm{P}}$} & $12.9 \%$ \\
\hline \multicolumn{2}{|c|}{ Activity A } & 0.79 \\
\hline \multicolumn{3}{|c|}{ Specific gravity of soil solids } \\
\hline & $\mathrm{G}_{\mathrm{s}}$ & 2.66 \\
\hline
\end{tabular}

time is sufficient to ensure a good distribution of moisture throughout the soil [5]. The moist soil was subsequently placed inside two plastic bags to prevent evaporation and left to equalize for at least one day so that moisture could redistribute across the soil. After this, the soil was placed inside a cylindrical mould with a diameter of $50 \mathrm{~mm}$ and compressed to the required pressure by using a load-controlled Zwick press with a capacity of $250 \mathrm{kN}$. Pressure was applied to the soil by two cylindrical aluminium pistons acting at the top and bottom of the specimen (Fig. 1). This double-piston compression action reduces the friction between the mould and the sample, thus increasing the uniformity of stresses inside the soil. A finely perforated aluminium disk and filter papers were placed between the top and bottom surfaces of the specimens and the respective pistons to facilitate drainage of pore air/water from the soil during compaction. Also, eight longitudinal fine grooves were cut along the lateral surfaces of the two pistons to create a preferential path for drainage at the interface between the outer surface of the pistons and the inner surface of the mould. More details about this compaction technique are available in Bruno et al. [12].

After compaction, specimens were cut down to a height of $100 \mathrm{~mm}$ by trimming the excess soil from the top and bottom extremities. The water content of the trimmed soil was measured by drying at $105^{\circ} \mathrm{C}$ until attainment of constant weight according to norm NF $\mathrm{P}$ 94-050 [19]. The water content of the specimen was then taken as the average of the top and bottom values. The water contents measured from the top and bottom trimmings were very similar suggesting that distribution moisture is uniform across the entire specimen.

Proctor compacted samples were obtained in compliance with the norm NF P 94-093 [20]. A fixed mass of 2250 gr of dry soil was mixed with the desired amount of water by means of a planetary mixer for at least 15 minutes and then stored for at least one day in two plastic bags. The moist soil was subsequently compacted in a standard Proctor mould in three layers.

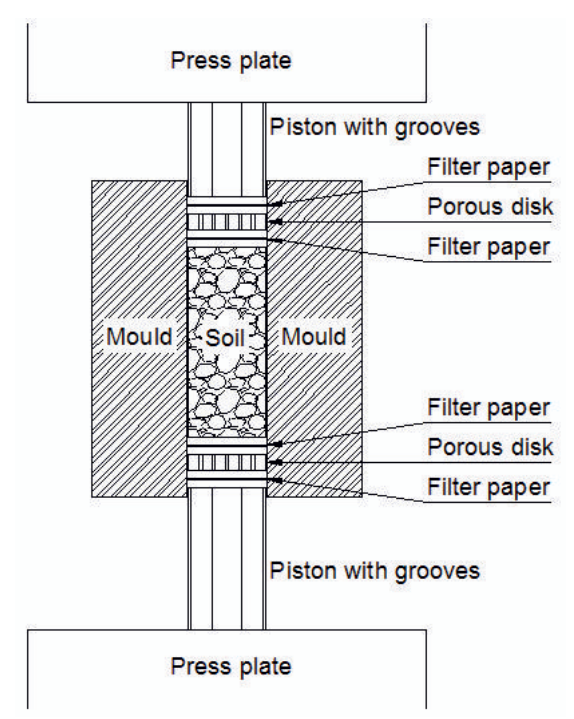

Figure 1. Hyper-compaction set-up 
Each layer was compacted by 25 blows of a 2.490 $\mathrm{kg}$ hammer falling from a fixed height of $305 \mathrm{~mm}$. After compaction, a cylindrical specimen of $50 \mathrm{~mm}$ diameter was cored from the larger Proctor sample. The cored specimen was then cut down to a height of $100 \mathrm{~mm}$ by trimming the excess soil from the top and bottom extremities. The remaining soil from the larger Proctor sample was used to determine the water content. Three samples of about $50 \mathrm{gr}$ each were taken at three different heights of the initial Proctor sample and dried at $105^{\circ} \mathrm{C}$ until weight became constant [19]. The water content was then determined as the average of these three measurements.

For each specimen, three measurements of diameter were taken at different heights and three measurements of height were taken at different angles. The volume of the sample was then calculated from the average values of diameter and height. The mass of the sample was finally measured by using a scale with a resolution of $0.01 \mathrm{~g}$. Based on the measured values of mass, water content, volume and specific gravity, it was possible to calculate bulk density, dry density, porosity and degree of saturation.

\section{Results}

\subsection{Compaction curves}

For each compaction level, the experimental values of dry density against the corresponding water contents are plotted in Fig. 2 together with the respective interpolating curves. For each compaction curve, the highest dry density corresponds to the optimum value of water content. The optimum water content becomes progressively smaller, while the corresponding density becomes progressively larger, as the compressive energy increases from Proctor compaction to static compaction at $25 \mathrm{MPa}, 50 \mathrm{MPa}$ and $100 \mathrm{MPa}$. This means that, as the effort increases, the compaction curve shift towards the theoretical point in which all porosity is erased and the dry density becomes equal to the density of the soil particles. The optimum dry density increases less than linearly with compaction pressure, i.e. the increase in dry density from $25 \mathrm{MPa}$ to $50 \mathrm{MPa}$ is greater than the increase in dry density from 50MPa to $100 \mathrm{MPa}$. It would therefore be necessary to apply an unfeasibly high pressure to attain the theoretical "no porosity" point.

Prior to mechanical testing, the compacted specimens were equalized inside a climatic chamber at a temperature of $25^{\circ} \mathrm{C}$ and relative humidity of $62 \%$. Equalization took about 15 days and was considered complete when the specimen mass changed less than $0.1 \%$ over at least one week. This equalisation stage prior to mechanical testing was considered essential to avoid any influence of different hygro-thermal conditions on the measured mechanical properties $[21 ; 22]$.

During equalization, all samples experienced desaturation and shrinkage as water content reduced to about 3.5\% and dry density increased, especially for the wetter samples. The specimens compacted at the highest pressure of $100 \mathrm{MPa}$ showed very similar values of dry density at the end of equalization (Fig. 3). This suggests that application of a high compaction pressure reduces the dependency of the material properties measured after equalization on the compaction water content, thus resulting in better quality control of the final product. On the contrary, samples manufactured at smaller pressures show, after equalization, variable values of dry densities depending on the water content at the time of compaction.

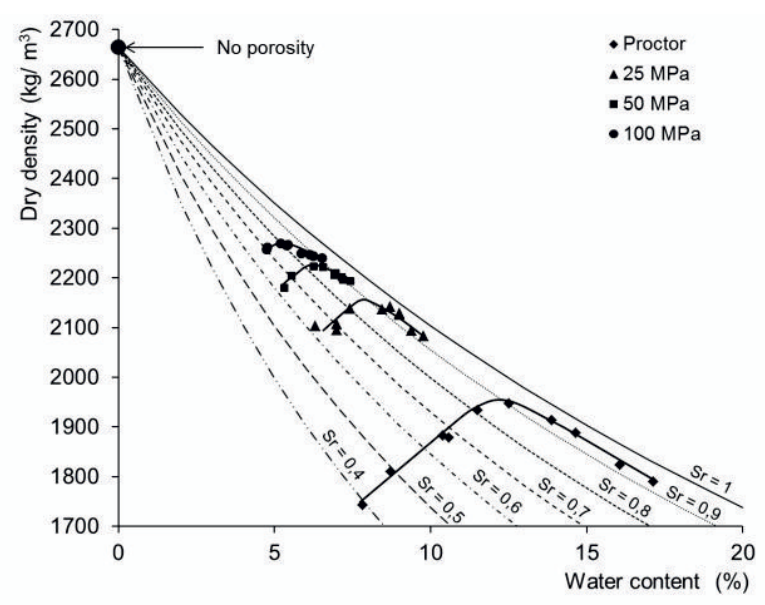

Figure 2. Comparison between standard Proctor compaction curve and hyper-compaction curves at $25 \mathrm{MPa}, 50 \mathrm{MPa}$ and 100 $\mathrm{MPa}$.

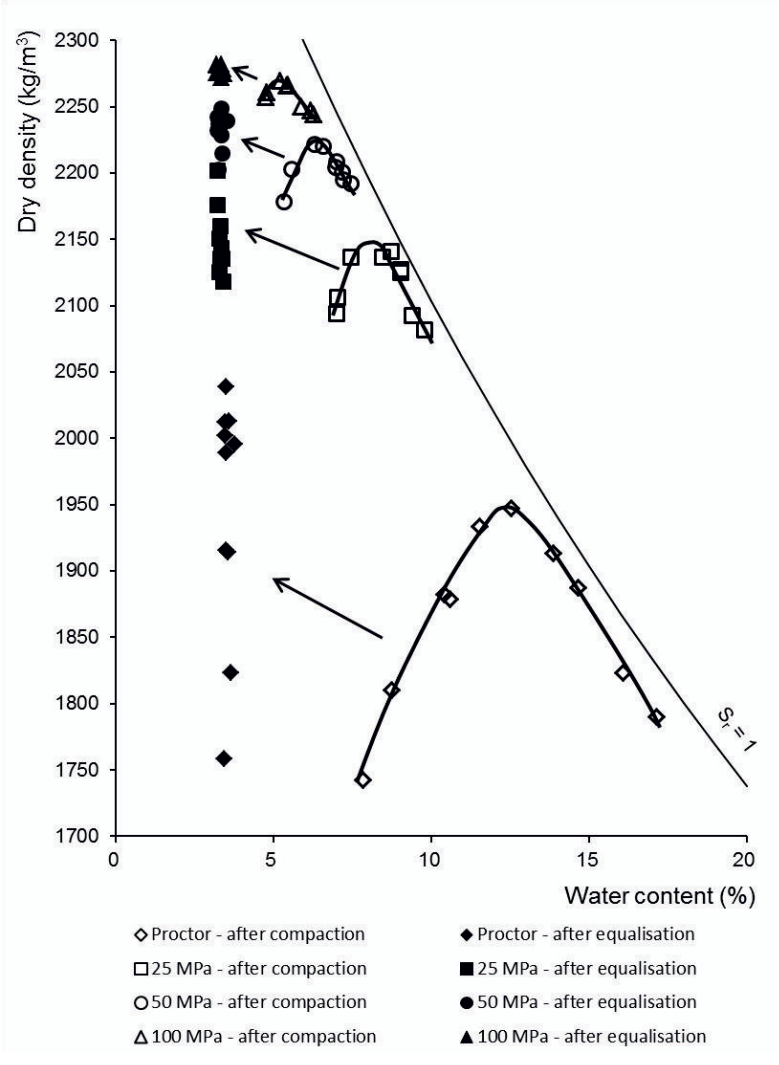

Figure 3. Change in dry density and water content during equalization. 


\subsection{Measurement of stiffness}

Young modulus was measured by performing five unconfined loading-unloading cycles, at a loading rate of $0.005 \mathrm{MPa} / \mathrm{s}$, between one ninth and one third of the estimated compressive strength (strength was estimated as the average value from two tests on randomly chosen samples for each compaction level). Axial displacements were measured between two points at a distance of 50 $\mathrm{mm}$ by means of two transducers placed on diametrically opposite sides of the specimen.

Due to the hysteretic response of the material during the loading-unloading cycles [5], the Young modulus was determined as the average slope of the unloading branches of the five cycles. This was based on the assumption that material behaviour is elasto-plastic during loading but essentially elastic during unloading.

Fig. 4 shows the values of Young modulus plotted against dry density for all specimens. Note that the values of dry density in Fig. 4 are those after equalisation (and hence before testing), which are shown in Fig. 3. Inspection of Fig.4 confirms the inadequacy of the Proctor compaction method to manufacture earthen materials with sufficient stiffness to be used in masonry construction. Conversely, the statically compacted specimens showed much higher values of Young modulus with a variation of one order of magnitude between the specimens compacted at $100 \mathrm{MPa}$ and those compacted according to Proctor.

Interestingly, Young modulus grows more than linearly with increasing dry density. Therefore, any small increase of dry density beyond the current maximum value of $2280 \mathrm{~kg} / \mathrm{m}^{3}$ would produce a significant augmentation of Young modulus. Of course, the dry density of the compacted specimens cannot be higher than the density of the soil particles (corresponding to the "no porosity" point in Fig. 2). In addition, the attainment of this theoretical limit is problematic from a practical point of view as previously discussed.

\subsection{Measurement of compressive strength}

The same specimens tested to measure Young modulus were subsequently loaded to failure to measure the unconfined compressive strength.

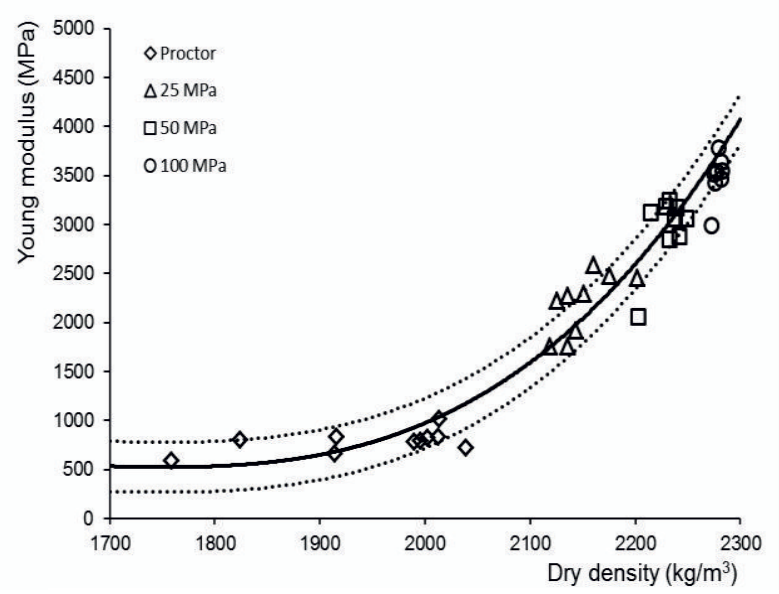

Figure 4. Variation of Young modulus with dry density
The accuracy of strength measurements can be affected by sample slenderness and friction with press plates $[23$, 24]. In this study, the slenderness ratio was equal to two (i.e. cylindrical specimens with height of $100 \mathrm{~mm}$ and diameter of $50 \mathrm{~mm}$ were used), which is considered sufficient to avoid measurements errors. In addition, Teflon spray was employed to reduce friction between the press plates and the specimen top and bottom surfaces. To avoid any dynamic effect, all tests were performed with a displacement rate of $0.001 \mathrm{~mm} / \mathrm{s}$, which was the slowest rate that could be applied by the press.

Fig. 5 shows the variation of the measured peak strength with dry density after equalization. Similar to the measurement of Young modulus, compressive strength increases more than linearly with increasing dry density. Thus, a small increase of dry density beyond the maximum value measured in this study could lead to a significant augmentation of compressive strength. Bruno et al. [12] showed that the compressive strength of specimens compacted at a pressure of $100 \mathrm{MPa}$ is already comparable with that of conventional masonry materials such as stabilised earth blocks and fired earth bricks.

\subsection{Mercury intrusion porosimetry tests}

After the measurement of compressive strength, small fragments of about 4 grams were taken from the failed specimens to perform mercury intrusion porosimetry (MIP) tests. These small specimens were re-equalised for a week at a temperature of $25^{\circ} \mathrm{C}$ and a relative humidity of $62 \%$ to avoid any potential change of material fabric caused by the environmental conditions inside the laboratory during testing. The small specimens were subsequently freeze-dried $[25,26]$ to remove all pore water without altering material fabric.

Freeze-drying consisted in dipping the specimens in liquid nitrogen $\left(-196^{\circ} \mathrm{C}\right)$ until boiling finished and then exposing them to vacuum at $-50^{\circ} \mathrm{C}$ of temperature for at least two days in order to sublimate the frozen pore water. After this, specimens were subjected to MIP tests and the results were interpreted according to Washburn equation :

$$
\Delta P=4 \gamma \cos \theta / d_{\text {pore }}
$$

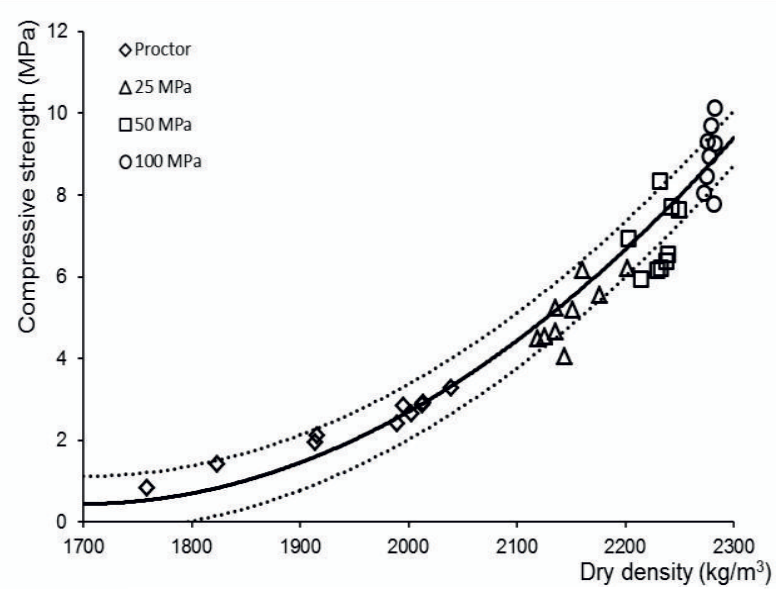

Figure 5. Variation of compressive strength with dry density 

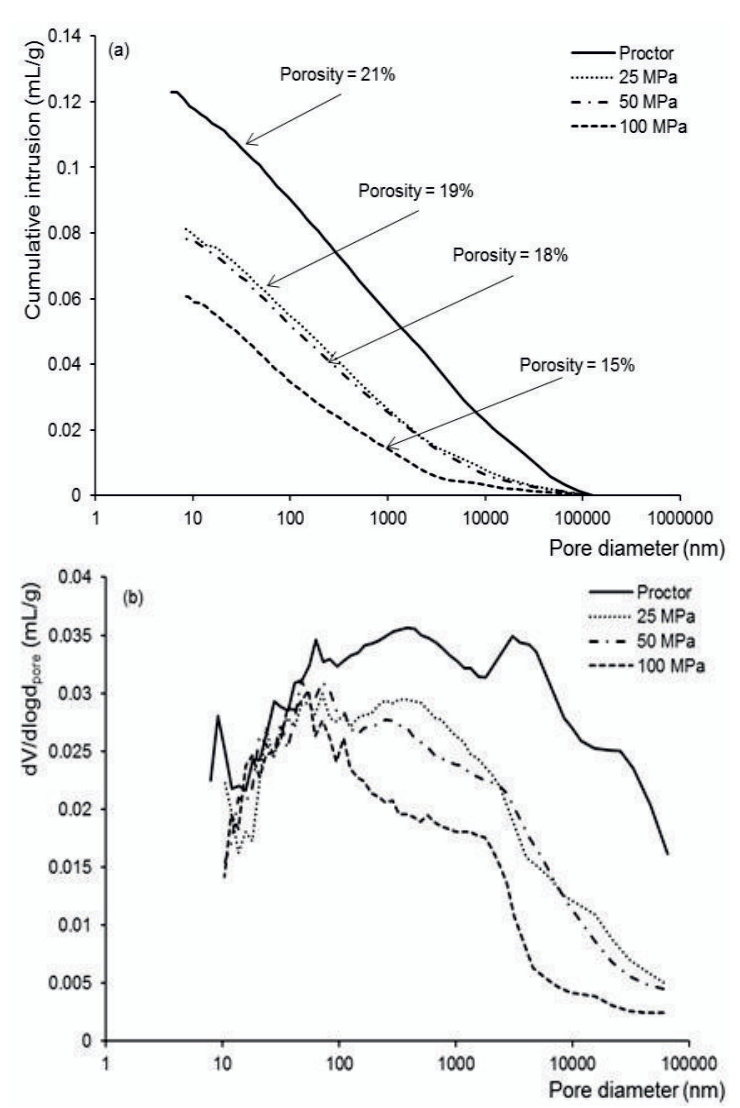

Figure 6. Cumulative volume and pore size distribution : comparison Proctor standard and high-pressure compaction.
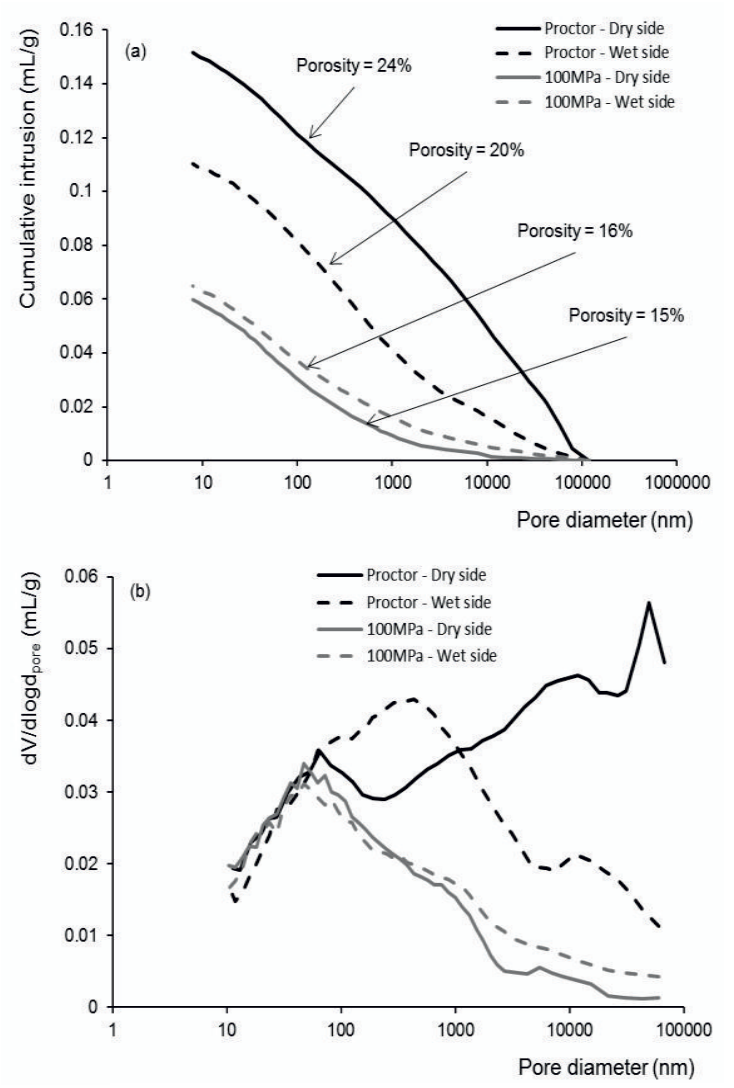

Figure 7. Cumulative volume and pore size distribution : comparison Proctor and $100 \mathrm{MPa}$.
By assuming cylindrical pores, Equation 1 allows the calculation of the pore diameter $d_{\text {pore }}$ as a function of the pressure difference across the mercury interface $\Delta P$, the mercury surface tension $\gamma$ and the mercury contact angle $\theta$. A surface tension of $485 \mathrm{dyn} / \mathrm{cm}$ and a contact angle of $147^{\circ}$ are assumed as suggested by Diamond [27] for illitic soils.

Figs. $6 \mathrm{a}$ and $6 \mathrm{~b}$ show the cumulative intruded volume and pore size distribution of specimens compacted, according to the different procedures, at their respective optimum water contents. Inspection of Fig. $6 \mathrm{a}$ indicates that the increase of compaction effort induces a large reduction in porosity, which is consistent with the observed differences in terms of mechanical properties. The increase of compaction effort affects the biggest pores (i.e. pores with diameter larger than $100 \mathrm{~nm}$ ) while the influence on smallest pores (i.e. pores with diameter smaller than $100 \mathrm{~nm}$ ) is very limited.

Figs. $7 \mathrm{a}$ and $7 \mathrm{~b}$ compare the cumulative intruded volume and pore size distribution of two specimens compacted according to the Proctor method and two specimens statically compacted at a pressure of $100 \mathrm{MPa}$. For each compaction method, the two specimens were chosen at the same dry density but on the dry and wet sides of the optimum water content, respectively. The two Proctor specimens exhibit different pore fabrics depending on the compaction water content. In particular, the specimen compacted wet of optimum shows a lower porosity than the one compacted dry of optimum. This is due to the significant shrinkage during equalisation. Conversely, the two specimens compacted at $100 \mathrm{MPa}$ show an almost identical pore fabric. This is consistent with the very similar dry densities and mechanical properties exhibited after equalization by all specimens compacted at $100 \mathrm{MPa}$ regardless of their compaction water content. This confirms that application of a high compaction pressure can standardize the material properties and reduce the variability associated to the compaction water content.

\section{Conclusions}

The paper has studied the influence of the compaction procedure on the mechanical and microstructural properties of unsaturated earthen materials. The standard Proctor compaction method has been compared with a high pressure "hyper-compaction" method developed by the authors for the manufacture of masonry bricks.

Results have showed that stiffness and strength increase more than linearly with increasing dry density. Hyper-compaction is capable of producing specimens with very high levels of dry density, never attained before for unstabilized earth materials. Mechanical tests confirmed that the hyper-compacted specimens exhibit values of strength and stiffness comparable to traditional building materials such as stabilized earth or fired bricks. Conversely, the lower compaction effort of the Proctor method is insufficient to generate mechanical properties suitable for masonry construction.

MIP tests have confirmed that, for a given compressive effort, the water content at the time of 
compaction affects the porosity of the material. However, this effect become progressively less significant as the compaction effort is increased from the Proctor standard to static compaction at $25 \mathrm{MPa}, 50 \mathrm{MPa}$ and $100 \mathrm{MPa}$. This means that the application of a very high pressure might lead to the manufacture of the same material regardless of the compaction water content.

Further analysis of the durability properties of the present soil are also planned in the continuation of this study.

\section{Acknowledgements}

The authors gratefully acknowledge the financial support from the Aquitaine Region (France) and the Agglomération Côte Basque-Adour (France).

\section{References}

1. M. Olivier and A. Mesbah. Bulletin de liaison du Laboratoire des Ponts et Chaussé, Paris, France, 146, 37-43 (1986).

2. B. V. Venkatarama Reddy and K. S. Jagadish. Géotechnique, 45, 363-367 (1995)

3. M.F. Attom. Appl. Clay Sci., 12 (1-2), 61-71 (1997).

4. A. Mesbah, J. C. Morel and A. Olivier. Mater. Struct. 32, 687-694 (1999).

5. C.H. Kouakou, J. C. Morel. Appl. Clay Sci., 44, 2734 (2009).

6. I. Garcia-Bengochea, A. G. Altschaeffl and C. W. Lovell. J. Geotech. Eng.-ASCE, 105 (7). 839-856 (1979).

7. H. Nowamooz and F. Masrouri. Eng. Geol., 114, 444-455 (2010).

8. AFNOR. XP P 94-041 (1995)

9. AFNOR. NF P 94-057 (1992).

10. AFNOR. NF P 94-051 (1993).
11. AFNOR. NF P 94-054 (1991)

12. A. W. Bruno, D. Gallipoli, C. Perlot, J. Mendes and N. Salmon. ICBBM, Clermont-Ferrand, France (2015).

13. M.C. Jiménez Delgado and I. Cañas Guerrero. Constr. Build. Mater., 21, 237-251(2007).

14. AFNOR. XP P13-901 (2001).

15. CRATerre-EAG, CDI, Brussels, Belgium (1998).

16. MOPT. Bases Para el Diseño y Construcción con Tapial. Madrid, Spain (1992).

17. A.W. Skempton. Proceedings $3^{\text {rd }}$ International Conference of Soil Mechanics and Foundation Engineering, 1, 57-60 [1953].

18. K. Dierks and C. Ziegert. In Steingass, P. : Moderner Lehmbau. Tagungsband, Fraunhofer IRB (2002).

19. AFNOR. NF P 94-050 (1995).

20. AFNOR. NF P 94-093 (1999).

21. C. T. S. Beckett and C. E. Augarde. In Proceedings of $2^{\text {nd }}$ European Conference on Unsaturated Soils; 287-292. Naples, Italy, Springer, ISBN: 978-3-64231342-4 (2012).

22. Q.-B. Bui, J. C. Morel, S. Hans and P. Walker. Constr. Build. Mater., 54, 163-169 (2014).

23. J. C. Morel, A. Pkla and P. Walker. Constr. Build. Mater., 21, 303-309 (2007).

24. D. Ciancio and J. Gibbings. Constr. Build. Mater., 28, 294-304 [2012].

25. E. Romero, A. Gens and A. Lloret. Eng. Geol. 54, 117-127 (1999).

26. O. Cuisinier and L. Laloui. Int. J. Numer. Anal. Met., 28, 483-499 (2004).

27. S. Diamond. Clay Clay Miner 18, 7-23 (1970) 